\title{
Potential impacts of soil microbiota manipulation on secondary metabolites production in cannabis
}

\author{
Bulbul Ahmed ${ }^{1}$ and Mohamed Hijri ${ }^{1,2^{*}}$ (D)
}

\begin{abstract}
Background: Cannabis growing practices and particularly indoor cultivation conditions have a great influence on the production of cannabinoids. Plant-associated microbes may affect nutrient acquisition by the plant. However, beneficial microbes influencing cannabinoid biosynthesis remain largely unexplored and unexploited in cannabis production.
\end{abstract}

Objective: To summarize study outcomes on bacterial and fungal communities associated with cannabis using highthroughput sequencing technologies and to uncover microbial interactions, species diversity, and microbial network connections that potentially influence secondary metabolite production in cannabis.

Materials and method: A mini review was conducted including recent publications on cannabis and their associated microbiota and secondary metabolite production.

Results: In this review, we provide an overview of the potential role of the soil microbiome in production of cannabinoids, and discussed that manipulation of cannabis-associated microbiome obtained through soil amendment interventions of diversified microbial communities sourced from natural forest soil could potentially help producers of cannabis to improve yields of cannabinoids and enhance the balance of cannabidiol (CBD) and tetrahydrocannabinol (THC) proportions.

Conclusion: Cannabis is one of the oldest cultivated crops in history, grown for food, fiber, and drugs for thousands of years. Extension of genetic variation in cannabis has developed into wide-ranging varieties with various complementary phenotypes and secondary metabolites. For medical or pharmaceutical purposes, the ratio of CBD to THC is key. Therefore, studying soil microbiota associated with cannabis and its potential impact on secondary metabolites production could be useful when selecting microorganisms as bioinoculant agents for enhanced organic cannabinoid production.

Keywords: Cannabis, Cannabinoid, Cannabidiol (CBD), Tetrahydrocannabinol (THC), Microbiota, Bioinoculants

\section{Introduction}

The Cannabis genus is comprised of two major groups of accessions: the indica gene pool and the sativa gene pool, which are closely related subspecies of Cannabis sativa

\footnotetext{
*Correspondence: Mohamed.Hijri@umontreal.ca

${ }^{1}$ Institut de Recherche en Biologie Végétale, Université de Montréal, 4101 Sherbrooke Est, Montréal, Québec H1X 2B2, Canada

Full list of author information is available at the end of the article
}

L. - although between these two subspecies, diverse cultivars have been domesticated throughout the hybridization process (Small and Cronquist, 1976; Emboden, 1981; Hillig, 2005). Regardless of evolutionary relationships, Cannabis is largely cultivated for medicinal and recreational use, and this has led to further categorization with regard to its relative cannabinoid concentrations, which broadly vary between the male and female plants (Small

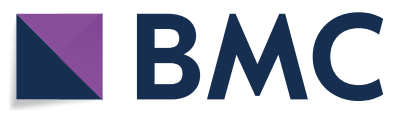

(C) The Author(s) 2021. Open Access This article is licensed under a Creative Commons Attribution 4.0 International License, which permits use, sharing, adaptation, distribution and reproduction in any medium or format, as long as you give appropriate credit to the original author(s) and the source, provide a link to the Creative Commons licence, and indicate if changes were made. The images or other third party material in this article are included in the article's Creative Commons licence, unless indicated otherwise in a credit line to the material. If material is not included in the article's Creative Commons licence and your intended use is not permitted by statutory regulation or exceeds the permitted use, you will need to obtain permission directly from the copyright holder. To view a copy of this licence, visit http://creativecommons.org/licenses/by/4.0/. 
and Cronquist, 1976; Emboden, 1981; Hillig, 2005). Over time, cultivation and breeding of Cannabis plants led to the expansion of genetic variations, resulting in a range of cultivars with contrasting phenotypes, traits and secondary metabolite properties (Li, 1973; Clarke and Merlin, 2017; Saloner and Bernstein, 2020; Danziger and Bernstein, 2021a, b; Shiponi and Bernstein, 2021). Despite technological advances in Cannabis breeding, the proportion of cannabinoids - or more specifically, of cannabidiol (CBD) and tetrahydrocannabinol (THC) fluctuate greatly depending on various factors, including the sex of the parents (male or female), genotypes, cultivation practices, and biotic or abiotic stresses (Backer, et al., 2019; Saloner and Bernstein, 2020; Danziger and Bernstein, 2021a, b). As a source of biotic stress, plant chemical compounds formed by signaling molecules from living organisms, as well as nutrient deficiency, water, and salt as an abiotic stressor may influence plant enzymatic pathways, altering the content of secondary metabolites (Pate, 1994; Gorelick and Bernstein, 2014, 2017; André, et al., 2020). That said, stress responses impact secondary metabolites such as alkaloids (Balsevich, et al., 1986; Facchini, 2001), terpenes (Trapp and Croteau, 2001; Pichersky and Raguso, 2018), and phenylpropanoids (Dixon and Paiva, 1995; Sharma, et al., 2019; Dong and Lin, 2021). Cannabis plants have attracted much attention for medical uses due to the importance of secondary metabolites, for which demand increased in the last decade following the discovery of the main compound present in Cannabis sativa - cannabinoids. Cannabinoids, a class of compounds specific to cannabis, are responsible for the vast majority of its medicinal activity (Gaoni and Mechoulam, 1964; Gorelick and Bernstein, 2017; Freeman, et al., 2019; Nelson, et al., 2020; LaVigne, et al., 2021). Here, we will simplify the potential of microbes for cannabinoid production, and how they could be manipulated for the stabilization of biosynthesis of different cannabinoids.

\section{Factors influencing the production of cannabinoids}

Cultivation methods and different abiotic and biotic factors are important considerations for cannabinoid biosynthesis. Variation in secondary metabolites of plant material is influenced by abiotic factors, for example, light, temperature, humidity, water availability, and nutrients (Krejci, 1970; Haney and Kutscheid, 1973; Bazzaz, et al., 1975; Coffman and Gentner, 1977; Valle, 1978; Lydon, et al., 1987; Pate, 1994; Bócsa, et al., 1997; Kakani, et al., 2003; Chandra, et al., 2011; Marti, et al., 2014; Magagnini, et al., 2018; Bernstein, et al., 2019; Landi, et al., 2019). As is the case for other plants, the growth and metabolism of cannabis are heavily affected by light spectra (Eaves, et al., 2020; Danziger and Bernstein, 2021a, b), with blue and red light having a significant impact on cannabinoid metabolism (Danziger and Bernstein, 2021a, b). Secondary metabolites including phenols, terpenes, flavonoids and anthocyanins are stimulated by UV radiation (Kakani, et al., 2003; Caldwell, et al., 2007; Backer, et al., 2019; Eichhorn Bilodeau, et al., 2019). UV-B radiation has been shown to increase THC concentrations (Lydon, et al., 1987) and UV-C radiation has been demonstrated to enhance the biosynthesis of cinnamic acids in cannabis (Marti, et al., 2014). Nonnitrogenous shikimic acid-dependent metabolites are more readily synthesized in the absence nutrients (Fluck, 1963; Waterman and Mole, 1989; Berenbaum, 1995, Nascimento NC and Fett-Neto, 2010). While the effect of nutrients on cannabinoid production is still not clear, soil conditions (Cooper, 2021); mineral and biostimulant substance amendments, for example nitrogen, iron, calcium and magnesium (Haney and Kutscheid, 1973; Kaneshima, et al., 1973; Latta and Eaton, 1975; Gorelick and Bernstein, 2017); and humic acids and NPK (Bernstein, et al., 2019) have been suggested as factors influencing THC content. NPK fertilizers have been shown to increase cannabigerol (CBG) concentrations by $71 \%$ in flowers and to decrease cannabinol (CBN) concentrations by $38 \%$ and $36 \%$ in flowers and inflorescence leaves, respectively. However, humic acids were shown to minimize the normal spatial heterogeneity of all cannabinoids analyzed (Bernstein, et al., 2019). Poor soil (Krejci, 1970), inadequate potassium, and moisture were found to increase THC production in hemp plants (Haney and Kutscheid, 1973). The effect of temperature on the production of cannabinoid is even more complicated because it is strain dependent (BRAUT, 1980) and may have both positive (Boucher, et al., 1974) and negative (Bazzaz, et al., 1975) effects in production of cannabinoids. Photomorphogenic behavior largely influences synthesization of cannabinoids in the glandular trichomes (Potter, 2009; Darko, et al., 2014; Eichhorn Bilodeau, et al., 2019).

Cannabinoids are unique secondary metabolites to Cannabis and are produced by trichomes of the plant. Although 61 true biosynthetic cannabinoids exist, Cannabis is generally cultivated for its CBD and THC, for both medicinal and recreational purposes. Previous studies have documented that the cannabinoid content in plants varies greatly depending on climatic conditions, plant genotypes, and cultivation practices that influence cannabinoid biosynthesis pathways (Small and Cronquist, 1976; Beutler and Marderosian, 1978). For example, high concentrations of THC in Cannabis plants were reported in cultivars originating from India, Nepal, Eastern Asia, and Southern Africa, while high concentrations of CBD were found in Northeast Asian cultivars (Fetterman and Turner, 1972; Small and Beckstead, 1973a, b; 
Small and Beckstead, 1973a, b; Turner and Hadley, 1973a, b; Turner and Hadley, 1973a, b; Baker, et al., 1980). However, as Cannabis is widely grown in indoor conditions with diverse growing substrates, artificial light, and temperature control, these factors are not sufficient to stabilize ratios of $\mathrm{THC}$ and $\mathrm{CBD}$ in the plants, which brings another level of complexity to cannabinoid production and standardization. Many possibilities have been explored by Cannabis growers in the effort to find a way to maintain the yield (Backer, et al., 2019) and safeguard production against pathogens (Taghinasab and Jabaji, 2020; Vujanovic, et al., 2020); however, scientific research for stabilization or balanced proportions of THC and $\mathrm{CBD}$ has not been reported. Among these solutions, biostimulant substances, beneficial microbes belonging to plant growth-promoting rhizobacteria (PGPR), and arbuscular mycorrhizal fungi have been proposed. Owing to previous legal limitations on cannabis cultivation, there is a lack of evidence on the use of microbes in cannabis production. Apart from that, microbes play an important role in the biosynthesis of cannabinoids and a deeper understanding of the relationship between microbes and production of cannabinoids is critical.

\section{Why should we consider microbial interactions for cannabinoid production?}

Advances made in high-throughput sequencing technologies offer possibilities for manipulating soil and plant microbiota to enhance crop yield and sustain agroecosystems (Ercolini, 2013; Lucaciu, et al., 2019; Fadiji and Babalola, 2020). Microbiota manipulation refers here to human intervention to alter the taxonomic composition and abundance of microbial communities associated with Cannabis plants. Bacteria and fungi are the two most important microbiota groups that closely or loosely interact with plants in a beneficial or adverse manner. Plants and their associated plethora of microbes nurture multifactorial interactive relationships where specific microorganisms including bacteria and fungi can stimulate the biosynthetic and signaling pathways of the host plants for the production of pharmaceutically or agronomically important metabolic compounds (Scherling, et al., 2009, van de Mortel, et al., 2012, Huang, et al., 2014, Ryffel, et al., 2016, Pascale, et al., 2019). Recent literature has shown that root-associated microbes stimulate the systematically induced root exudation of metabolites (SIREM) process and affect levels of root transcriptomes and metabolomes (Korenblum, et al., 2020). Endophytic bacteria and fungi can influence the metabolic machinery for producing a specific medicinal compound. For example, the pharmaceutically essential terpenoid indole type alkaloids vindoline, serpentine, and ajmalicine showed a substantial increase when Madagascar periwinkle
(Catharanthus roseus L.) plants were inoculated with the endophytic bacteria Staphylococcus sciuri and Micrococcus sp. (Etalo, et al., 2018). Recent analysis (Taghinasab and Jabaji, 2020) addressed the use of exogenous inducers such as phytohormones abscisic acid (ABA), gibberellins (GA), and ethylene (ET) on the possible recovery of secondary metabolites in cannabis. Few bacterial (Pseudonomas fulva BTC8-1, P. orientalis BTG8-5, and Panibacillus $s p$. MOSEL-w13) and fungal endophytes (Penicillium copticola L3, Paecilomyces lilacinus A3, and Alternaria niger 2) in cannabis have demonstrated their potential biocontrol effects against Trichothecium roseum, Botrytis cineria, Fusarium solani, Curvularia lunata, Aspergillus niger, and Fusarium oxysporum (Kusari, et al., 2012; Gautam, et al., 2013; Qadri, et al., 2013; Afzal, et al., 2015; Scott, et al., 2018). It has been shown that transferring PGPR from one crop to another plant species may stimulate yield and biocontrol effects (Smith, et al., 2015; Backer, et al., 2019), and the collective role of endophytes with the exogenous application of inducers in cannabis could stimulate improvement of THC and CBD content, though its correlation and mechanism have not yet been fully revealed (Taghinasab and Jabaji, 2020). These authors did not discuss how the entire microbiome (not only the endophytes) associated with cannabis root could be effectively used in manipulation of the cannabinoid profile. PGPR has attracted scientists' attention for its potential to increase the quality and quantity of production of desired cannabinoids; however, in most cases, scientists have focused on well-known PGPR genera, for example, Pseudomonas and Bacillus for cannabinoid yield and disease control effects demonstrated in other crops (Lyu, et al., 2019). Microbiota are genotype-specific for a variety of beneficial functions, such as nutrient acquisition, stress response, pathogen tolerance, and secondary metabolite biosynthesis (Liu, et al., 2019; Brown, et al., 2020). As a result, complex signal coordination between the host and associated microbes is evident in particular plant-microbe interactions, contributing to overall understanding of plant-specific microbial inputs. Different microbes can colonize various areas of the root, increasing the total root biomass and nutrient acquisition capacity. Some microbial strains protect plants against pathogen attacks, while others improve the resilience and recovery of plants subjected to stress. Advances made in high-throughput sequencing and bioinformatics have made it possible to search for microbial genes present in a given environmental sample for novel functions that can influence the production of bioactive compounds (Fernández-Arrojo, et al., 2010). Beneficial microbes recruited by plant genotypes can be discovered using diversified microbial communities derived from the natural environment. For example, natural microbial 
amendments from undisturbed and old growth maple forest organic soil showed an increased phosphorus acquisition in soybean plants (unpublished data). Since the interplay between the microbes and plant stimulates various biochemical pathways, leading to the production of secondary metabolites, as a result, decoding the community profile of cannabis-associated microbes would produce a large list of microbes to choose from and its microbiota would unravel the complexity of stabilizing cannabinoid production.

\section{Current knowledge in microbiota research related to cannabinoids}

The first draft genome sequencing of Cannabis solved one of the utmost ambiguities - that although they contain divergent pharmaceutical compounds, marijuana and hemp are derived from a single species: Cannabis sativa $L$. In addition, the genomic map provides clues to the scientific community for accelerating breeding programs to develop new cultivars with improved properties (van Bakel, et al., 2011). The first report on the Cannabis plant microbiome highlighted cultivar-specificity and soil determinants of the microbiome for five Cannabis cultivars - Bookoo Kush, Burmese, Maui Wowie, White Widow, and Sour Diesel - and reported a core bacterial community composed of Pseudomonas, Cellvibrio, Oxalobacteraceae, Xanthomonadaceae, Actinomycetales, and Sphingobacteriales (Winston et al., 2014). This study included the biochemical correlations with bacterial communities, highlighting that the concentration and composition of CBD were correlated with the structure of bacterial communities residing inside the root system, whereas THC concentrations were correlated with the soil's edaphic factors. Another study on three Cannabis sativa L. (industrial hemp) cultivars grown in Quebec (Anka, CRS-1, and Yvonne) reported 18 bacterial and 13 fungal endophytic isolates, of which three bacterial genera of Pseudomonas, Pantoea, and Bacillus and three fungal genera of Aureobasidium, Alternaria, and Cochliobolus were found to be widely distributed in the above-ground tissues (Scott, et al., 2018). Further experiments are needed to validate the effects of these isolates on Cannabis growth and secondary metabolite production. Of the microbial inoculants engineered for Cannabis production, Mammoth $\mathrm{P}^{\mathrm{TM}}$ is an example of microbial biostimulants used to improve bud growth, yield, and plant biotic stress (Conant, et al., 2017). The authors reported that using Mammoth $\mathrm{P}^{\mathrm{TM}}$ in Cannabis sativa resulted in a $16.5 \%$ increase in plant aerial biomass, but no connection to cannabinoid synthesis was found.

The first report on spatiotemporal and cultivardependent divergences in indoor commercial settings showed variations in the bacterial and fungal microbiome of C. sativa. The study included three cultivars - CBD Yummy, CBD Shark, and Hash - and was carried out in strict indoor commercial settings (Comeau, et al., 2020). The experiment was conducted without the use of microbial inoculants. The study investigated spontaneous microbes that established themselves during the growth of Cannabis plants. Nonetheless, they found that microbial communities evolved over time and differed between Cannabis strains. Penicillium, Aspergillus, Zopfiella, and Fusarium genera of Ascomycota and Basidiomycota were recognized as the dominant fungi while Burkholderiaceae and Rhizobiaceae of the phylum Proteobacteria, and Streptomycetaceae and Norcardiodaceae of the phylum Actinobacteria were the dominant bacteria. The metabolic profiling linking microbes associated with the rhizosphere were not quantified in the study. The metabolic pathway was predicted based on bacterial abundance linked to glucose, pentose, lipid, and amino acid metabolism, but this was not verified (Comeau, et al., 2020).

Plant microbiomes are dynamic and can change in response to external factors. The first study of PGPR application showed positive impact on CBD and THC content in C. sativa "Finola" (Pagnani, et al., 2018); however, microbes modulating plant metabolites in a number of other crops can be applied to cannabis. For example, a consortium containing Bacillus sp., Streptomyces sp., Pseudomonas sp., Azospirillum sp., and an arbuscular mycorrhiza fungus Glomus sp. has been reported to affect the composition of secondary metabolites in maize (Walker, et al., 2011, 2012; Couillerot, et al., 2013). Pseudomonas aeruginosa PJHU15, Bacillus subtilis BHHU100, and Trichoderma harzianum TNHU27 increased phenol levels in pea plants (Jain, et al., 2015). Root-secreted secondary metabolites play a significant role in plant-soil microbiome interactions (Sasse, et al., 2018). Some microbes have the potential to adjust individual output by influencing the local environment (Köberl, et al., 2013, Hu, et al., 2018, Huang, et al., 2018). Secondary metabolites in maize, such as benzoxazinoids, have been shown to attract Chloroflexi bacteria and manipulate the assembly of maize microbiomes, which enhanced the resilience of maize plants against stress (Hu, et al., 2018). Methylobacterium sp. has been found to play a role in modulating the production of flavorrelated phytometabolites (Brader, et al., 2014). Trichoderma harzianum has been shown to increase the root system (Harman, 2011; Guzmán-Guzmán, et al., 2019; Vicente, et al., 2020), biomass accumulation, and water content (Oljira, et al., 2020) in a variety of crops including wheat, soybean, and cucumber. In the same way, $T$. harzianum increased CBD content as well as biomass in hemp (Kakabouki, et al., 2021). 


\section{Determining core microbiota could enhance and sustain cannabinoids}

In this context, the core microbiota is defined as a microbial community common and essential to all healthy Cannabis plants. This core microbiota is anticipated to give indispensable indicators of crucial soil processes, of links between microbiota and their functional attributes (Delgado-Baquerizo, et al., 2018), and of soil microbial communities (Zamioudis and Pieterse, 2011; Lebeis, 2014). Plant genotype plays a key role in shaping the microbial communities of the rhizosphere (Marques, et al., 2014; Sapkota, et al., 2015). Plant root bound microbes are so crucial for plant health that they are often referred to as the second genome of the plant (Berendsen, et al., 2012). As a result, selecting microbes that enhance nutrient security, plant health, and chemical compound biosynthesis for a particular genotype is critical. Despite being linked to below-ground nutrient cycling, genotype plays a vital ecological role in maintaining complex interactions between microbial taxa. However, due to competition with native soil microbial communities or impaired colonization performance, the introduction of unspecified microbes may be ineffective or have an antagonistic effect (Qin, et al., 2016). The core microbiota could be a baseline for selecting beneficial microbes, whose communities could then be manipulated to enhance the desired functions and services of plant hosts such as biochemical compound production. To do so, we must prioritize studies of the composition of the cannabis microbial community and the factors that influence it at different stages of development. Microbial populations are diverse and are influenced by growth stages and cultivation conditions. Many studies examine a variety of root-associated microbial communities - for example, mycorrhizal fungi and their associated microbes - that promote plant growth in an agricultural context (Ismail and Hijri, 2012; Hijri, 2016; Zarik, et al., 2016) or the microbial community in contaminated environments (Hassan, et al., 2013; Bell, et al., 2014; Bourdel, et al., 2016; Iffis, et al., 2017; Dagher, et al., 2019, 2020). Such studies could be adapted and applied to marijuana and industrial hemp so as to decipher the underlying core microbiota.

Many recent studies have shown the potential of manipulation of soil microbial communities to enhance yields and sustain agroecosystems for different crops, such as corn, wheat and soybeans (Renaut, et al., 2020); blueberries (Morvan, et al., 2020); and canola (Floc'h, et al., 2020). A study demonstrated that a natural microbial suspension prepared from an undisturbed old maple forest and used as a soil amendment increased soybean biomass and phosphorus acquisition by hydrolyzing phytate (unpublished data). This suggests that microberich natural soil could be applied as a soil amendment to manipulate cannabinoid production in cannabis. Here, we present a technical workflow for decoding the microbial community structure of Cannabis and using it to identify core microbiota, which can then be tested and validated for cannabinoid production. Members of the core microbiota should be tested for compatibility, synergy, plant growth-promoting activities, and positive correlation with secondary metabolite production. We propose that Cannabis plants recruit their specific core microbiota when they are inoculated with a microbial suspension prepared from naturally microbial-rich environments such as forest soils. Amplicon sequencing targeting the bacterial 16S rRNA gene, the fungal ITS gene, and the fungal 18S rRNA gene, coupled with whole metagenome and/or metatranscriptome using high-throughput sequencing (e.g., Illumina platforms), will allow us to decipher the microbial communities and their spatiotemporal changes in different Cannabis cultivars. Ecology of soil microbial network analyses within community (Kurtz, et al., 2015) and interkingdom interaction (Hartman, et al., 2018; Floc'h, et al., 2020) correlation based on the occurrence of microbial species will assist us in finding hub microbial taxa across cultivars. These hub taxa will be the candidates for identifying core microbes influencing plant growth and cannabinoid biosynthesis (Fig. 1), while evidence of the hub microbial species will serve as a first step toward screening microbes exclusively for cannabinoid stabilization.

\section{Conclusions}

Cannabis has been banned by various countries around the globe over many centuries, limiting research and development of its cultivation. Cannabis cultivation is highly variable on a global scale, but cultivation practices can greatly influence yield and cannabinoid quality even in the same cultivar. Mounting concerns regarding stable and sustained cannabinoid production have recently drawn the focused attention of scientists. Our main purpose here is to speculate on the most sustainable way to minimize the imbalance of cannabinoid production in Cannabis. Therefore, contingent upon high-throughput research, we propose that studies to decode microbial communities and their interactions with Cannabis plants would be a promising way to formulate bioinoculants for improvement of cannabis quality in sustainable agricultural practices. Although beneficial microbes for biomass improvement are available for other plant species, the practice of microbe-based organic farming for cannabis cultivation is still in its infancy. We propose that the identification of core microbiota and their correspondence with secondary metabolites production through metagenomics in combination with metabolomics will offer new leads for exploring the underlying mechanisms 


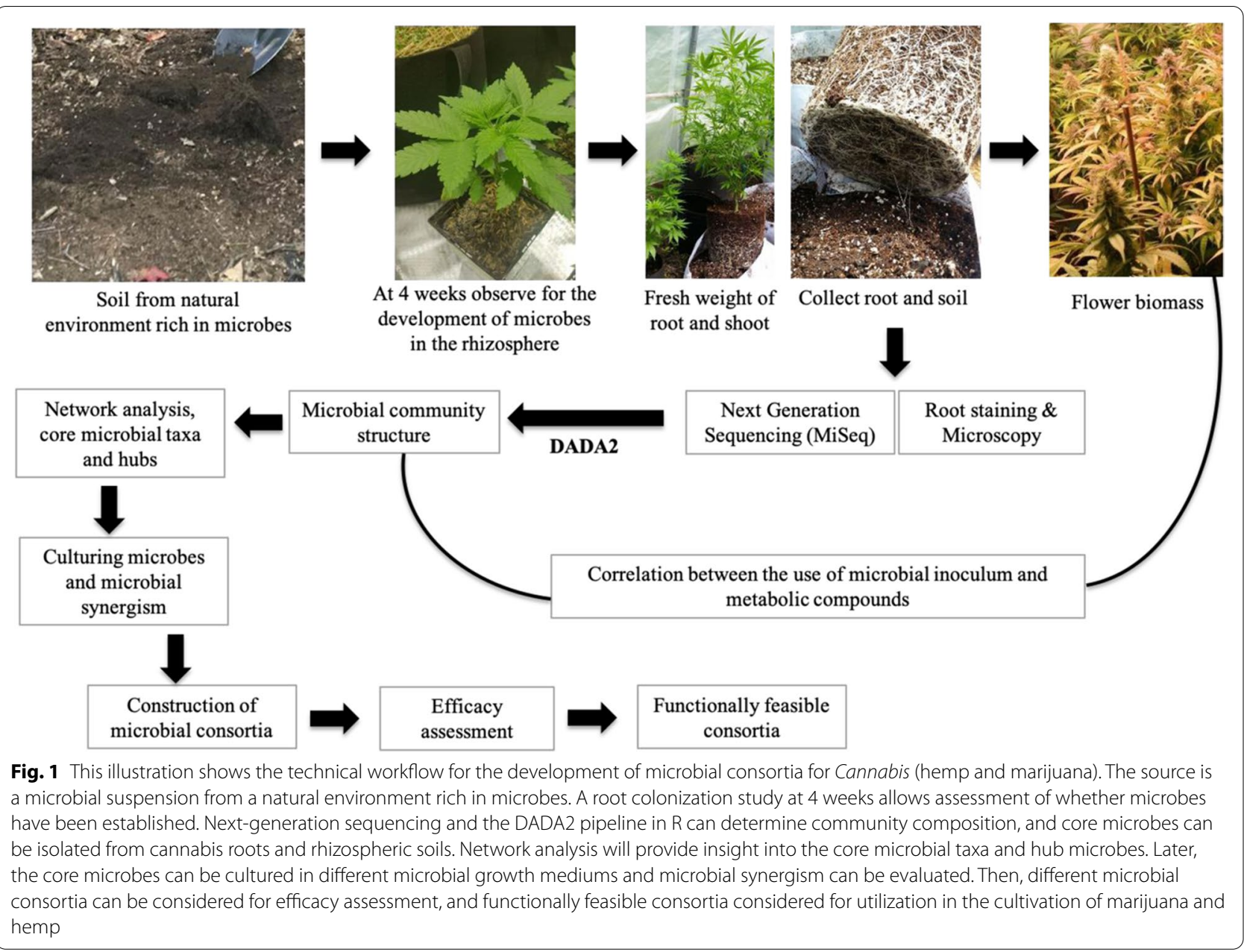

of Cannabis cultivation for improved, sustainable, and stable production of cannabinoids. Conclusively, deeper understanding of microbiota-biochemical talk may rationalize our current gaps in knowledge regarding correlating microbial mechanisms for stabilization of cannabinoid biosynthesis.

\section{Abbreviations}

CBD: Cannabidiol; CBG: Cannabigerol; CBN: Cannabinol; THC: Tetrahydrocannabinol; PGPR: Plant growth-promoting rhizobacteria; SIREM: Systematically induced root exudation of metabolites; ABA: Abscisic acid; GA: Gibberellins; ET: Ethylene.

\section{Acknowledgements}

Not applicable.

\section{Authors' contributions}

BA: Conceptualization and writing of the manuscript. MH: Conceptualization, funding acquisition, supervision, and revision of the manuscript. The author(s) read and approved the final manuscript.

\section{Funding}

This study was supported by a Fonds de Recherche du Québec-Nature et technologies (FRQNT) B3X fellowship (received by BA) and a Natural Sciences and Engineering Research Council (NSERC) Discovery grant (received by MH). Health Canada issued license number LIC-QB7LHCB3BL-2020 to MH in accordance with the Cannabis Act and Cannabis Regulations.

\section{Availability of data and materials \\ Not applicable.}

\section{Declarations}

Ethics approval and consent to participate

This study does not involve use of animals for experimental studies.

\section{Consent for publication}

Not applicable.

\section{Competing interests}

Both authors (BA and $\mathrm{MH}$ ) work for the Institut de Recherche en Biologie Végétale, Université de Montréal.

\section{Author details}

${ }^{1}$ Institut de Recherche en Biologie Végétale, Université de Montréal, 4101 Sherbrooke Est, Montréal, Québec H1X 2B2, Canada. ${ }^{2}$ African Genome Center, Mohammed VI Polytechnic University (UM6P), Lot 660, Hay Moulay Rachid, 43150 Ben Guerir, Morocco.

Received: 30 November 2020 Accepted: 22 June 2021

Published online: 03 July 2021 


\section{References}

Afzal I, Shinwari ZK, Iqrar I. Selective isolation and characterization of agriculturally beneficial endophytic bacteria from wild hemp using canola. 2015.

André A, Leupin M, KneubühI M, Pedan V, Chetschik I. Evolution of the polyphenol and terpene content, antioxidant activity and plant morphology of eight different fiber-type cultivars of Cannabis sativa L. cultivated at three sowing densities. Plants. 2020;9:1740.

Backer R, Schwinghamer T, Rosenbaum P, McCarty V, Eichhorn Bilodeau S, Lyu $D$, et al. Closing the yield gap for cannabis: a meta-analysis of factors determining cannabis yield. Front Plant Sci. 2019;10:495.

Baker P, Gough T, Taylor B. Illicitly imported cannabis products: some physical and chemical features indicative of their origin. Bull Narc. 1980;32:31-40.

Balsevich J, DeLuca V, KURZ, W.W. . Altered alkaloid pattern in dark grown seedlings of Catharanthus roseus: the isolation and characterization of 4-desacetoxyvindoline: a novel indole alkaloid and proposed precursor of vindoline. Heterocycles (sendai). 1986;24:2415-21.

Bazzaz F, Dusek D, Seigler D, Haney A. Photosynthesis and cannabinoid content of temperate and tropical populations of Cannabis sativa Biochem Syst Ecol. 1975;3:15-8.

Bell TH, El-Din Hassan S, Lauron-Moreau A, Al-Otaibi F, Hijri M, Yergeau E, StArnaud M. Linkage between bacterial and fungal rhizosphere communities in hydrocarbon-contaminated soils is related to plant phylogeny. ISME J. 2014:8:331-43.

Berenbaum MR. The chemistry of defense: theory and practice. Proc Natl Acad Sci. 1995;92:2-8.

Berendsen RL, Pieterse CM, Bakker PA. The rhizosphere microbiome and plant health. Trends Plant Sci. 2012;17:478-86.

Bernstein N, Gorelick J, Zerahia R, Koch S. Impact of N, P, K, and Humic Acid Supplementation on the Chemical Profile of Medical Cannabis (Cannabis sativa L). Front Plant Sci. 2019;10:736.

Beutler JA, Marderosian AH. Chemotaxonomy of Cannabis I. Crossbreeding between Cannabis sativa and C. ruderalis, with analysis of cannabinoid content. Econ Bot. 1978;32:387.

Bócsa I, Máthé P, Hangyel L. Effect of nitrogen on tetrahydrocannabinol (THC) content in hemp (Cannabis sativa L.) leaves at different positions. J Int Hemp Assoc. 1997:4:78-9.

Boucher F, Cosson L, Unger J, Paris M. Le Cannabis sativa L.; races chemiques oiu varietes. PI Med Phytoterap. 1974;8:20-31.

Bourdel G, Roy-Bolduc A, St-Arnaud M, Hijri M. Concentration of petroleumhydrocarbon contamination shapes fungal endophytic community structure in plant roots. Front Microbiol. 2016;7:685.

Brader G, Compant S, Mitter B, Trognitz F, Sessitsch A. Metabolic potential of endophytic bacteria. Curr Opin Biotechnol. 2014;27:30-7.

Braut-Boucher F. Effet des conditions écophysiologiques sur la croissance, le développement et le contenu en cannabinoïdes des clones correspondant auxdeux types chimiques du Cannabis sativa L. originaire d'Afrique du Sud. Physiol vég. 1980;207-21.

Brown SP, Grillo MA, Podowski JC, Heath KD. Soil origin and plant genotype structure distinct microbiome compartments in the model legume Medicago truncatula Microbiome. 2020;8:139.

Caldwell MM, Bornman J, Ballaré C, Flint SD, Kulandaivelu G. Terrestrial ecosystems, increased solar ultraviolet radiation, and interactions with other climate change factors. Photochem Photobiol Sci. 2007;6:252-66.

Chandra S, Lata H, Khan IA, Elsohly MA. Temperature response of photosynthesis in different drug and fiber varieties of Cannabis sativa L. Physiol Mol Biol Plants. 2011;17:297-303.

Clarke RC, Merlin MD. Cannabis domestication, breeding history, presentday genetic diversity, and future prospects. Crit Rev Plant Sci. 2017;35:293-327.

Coffman C, Gentner W. Responses of greenhouse-grown Cannabis sativa L. to nitrogen, phosphorus, and potassium 1. Agron J. 1977;69:832-6.

Comeau D, Novinscak A, Joly DL, Filion M. Spatio-temporal and cultivardependent variations in the cannabis microbiome. Front Microbiol. 2020;11:491.

Conant RT, Walsh RP, Walsh M, Bell CW, Wallenstein MD. Effects of a Microbial Biostimulant, Mammoth PTM, on Cannabis sativa Bud Yield. J Hortic. 2017;4:191. https://doi.org/10.4172/2376-0354.100019.

Cooper TJ. A greenhouse study evaluating nutrient uptake and the production of industrial hemp in soils cultivated with loblolly pine. 2021. https:// repository.lib.ncsu.edu/bitstream/handle/1840.20/38596/etd.pdf?seque nce $=1$ \&isAllowed $=y$.

Couillerot O, Ramírez-Trujillo A, Walker V, von Felten A, Jansa J, Maurhofer M, et al. Comparison of prominent Azospirillum strains in AzospirillumPseudomonas-Glomus consortia for promotion of maize growth. Appl Microbiol Biotechnol. 2013;97:4639-49.

Dagher DJ, de la Providencia IE, Pitre FE, St-Arnaud M, Hijri M. Plant identity shaped rhizospheric microbial communities more strongly than bacterial bioaugmentation in petroleum hydrocarbon-polluted sediments. Front Microbiol. 2019;10:2144.

Dagher DJ, Pitre FE, Hijri M. Ectomycorrhizal fungal inoculation of sphaerosporella brunnea significantly increased stem biomass of salix miyabeana and decreased lead, tin, zinc, soil concentrations during the phytoremediation of an ilndustrial landfill. J Fungi. 2020;6(2):87. https:// doi.org/10.3390/jof6020087.

Danziger N, Bernstein N. Light matters: Effect of light spectra on cannabinoid profile and plant development of medical cannabis (Cannabis sativa L.). Indust Crops Products. 2021;164:113351.

Danziger N, Bernstein N. Plant architecture manipulation increases cannabinoid standardization in 'drug-type' medical cannabis. Indust Crops Products. 2021;167:113528.

Darko E, Heydarizadeh P, Schoefs B, Sabzalian MR. Photosynthesis under artificial light: the shift in primary and secondary metabolism. Philos Transact Royal Soc B Biol Sci. 2014;369:20130243.

Delgado-Baquerizo M, Oliverio AM, Brewer TE, Benavent-González A, Eldridge DJ, Bardgett RD, et al. A global atlas of the dominant bacteria found in soil. Science. 2018;359:320.

Dixon RA, Paiva NL. Stress-induced phenylpropanoid metabolism. Plant Cell. 1995:7:1085.

Nascimento NC, Fett-Neto AG. Plant secondary metabolism and challenges in modifying its operation: an overview. Methods Mol Biol. 2010;643:1-13. https://doi.org/10.1007/978-1-60761-723-5_1.

Dong NQ, Lin HX. Contribution of phenylpropanoid metabolism to plant development and plant-environment interactions. J Integr Plant Biol. 2021;63:180-209.

Eaves J, Eaves S, Morphy C, Murray C. The relationship between light intensity, cannabis yields, and profitability. Agron J. 2020;112:1466-70.

Eichhorn Bilodeau S, Wu BS, Rufyikiri A-S, MacPherson S, Lefsrud M. An update on plant photobiology and implications for cannabis production. Front Plant Sci. 2019;10:296. https://doi.org/10.3389/fpls.2019.00296.

Emboden WA. The genus Cannabis and the correct use of taxonomic categories. J Psychoactive Drugs. 1981;13:15-21.

Ercolini D. High-throughput sequencing and metagenomics: moving forward in the culture-independent analysis of food microbial ecology. Appl Environ Microbiol. 2013;79:3148-55.

Etalo DW, Jeon JS, Raaijmakers JM. Modulation of plant chemistry by beneficial root microbiota. Nat Prod Rep. 2018:35:398-409.

Facchini PJ. Alkaloid biosynthesis in plants: biochemistry, cell biology, molecular regulation, and metabolic engineering applications. Annu Rev Plant Biol. 2001;52:29-66.

Fadiji AE, Babalola OO. Metagenomics methods for the study of plantassociated microbial communities: a review. J Microbiol Methods. 2020:170:105860.

Fernández-Arrojo L, Guazzaroni M-E, López-Cortés N, Beloqui A, Ferrer M. Metagenomic era for biocatalyst identification. Curr Opin Biotechnol. 2010;21:725-33.

Fetterman PS, Turner CE. Constituents of Cannabis sativa L. I: propyl homologs of cannabinoids from an Indian variant. J Pharm Sci. 1972:61:1476-7.

Floc'h JB, Hamel C, Lupwayi N, Harker KN, Hijri M, St-Arnaud M. Bacterial Communities of the Canola Rhizosphere: Network analysis reveals a core bacterium shaping microbial interactions. Front Microbiol. 2020;11:1587. https://doi.org/10.3389/fmicb.2020.01587.

Fluck $\mathrm{H}$. Intrinsic and extrinsic factors affecting the production of secondary plant products. Chem Plant Taxon. 1963;1:167-86.

Freeman TP, Hindocha C, Green SF, Bloomfield MAP. Medicinal use of cannabis based products and cannabinoids. BMJ. 2019;365:11141.

Gaoni Y, Mechoulam R. Isolation, structure, and partial synthesis of an active constituent of hashish. J Am Chem Soc. 1964;86:1646-7.

Gautam AK, Kant M, Thakur Y. Isolation of endophytic fungi from Cannabis sativa and study their antifungal potential. Arch Phytopathol Plant Prot. 2013:46:627-35. 
Gorelick J, Bernstein N. Chemical and Physical Elicitation for Enhanced Cannabinoid Production in Cannabis. In: Chandra S., Lata H., ElSohly M. (eds) Cannabis sativa L. - Botany and Biotechnology. Cham: Springer; 2017. https://doi.org/10.1007/978-3-319-54564-6_21.

Gorelick J, Bernstein N. Elicitation: an underutilized tool in the development of medicinal plants as a source of therapeutic secondary metabolites. Adv Agron. 2014;124:201-30.

Guzmán-Guzmán P, Porras-Troncoso MD, Olmedo-Monfil V, Herrera-Estrella A. Trichoderma species: versatile plant symbionts. Phytopathology. 2019;109:6-16.

Haney A, Kutscheid BB. Quantitative variation in the chemical constituents of marihuana from stands of naturalized Cannabis sativa L. in eastcentral Illinois. Econ Bot. 1973;27:193-203.

Harman GE. Trichoderma — not just for biocontrol anymore. Phytoparasitica. 2011;39:103-8.

Hartman K, van der Heijden MGA, Wittwer RA, Banerjee S, Walser JC, Schlaeppi K. Cropping practices manipulate abundance patterns of root and soil microbiome members paving the way to smart farming. Microbiome. 2018;6:14.

Hassan SE, Hijri M, St-Arnaud M. Effect of arbuscular mycorrhizal fungi on trace metal uptake by sunflower plants grown on cadmium contaminated soil. New Biotechnol. 2013;30:780-7.

Hijri M. Analysis of a large dataset of mycorrhiza inoculation field trials on potato shows highly significant increases in yield. Mycorrhiza. 2016;26:209-14.

Hillig KW. Genetic evidence for speciation in Cannabis (Cannabaceae). Genet Resour Crop Evol. 2005;52:161-80.

Hu L, Robert CAM, Cadot S, Zhang X, Ye M, Li B, et al. Root exudate metabolites drive plant-soil feedbacks on growth and defense by shaping the rhizosphere microbiota. Nat Commun. 2018;9:2738.

Huang S, Zhang J, Tao Z, Lei L, Yu Y, Huang L. Enzymatic conversion from pyridoxal to pyridoxine caused by microorganisms within tobacco phyllosphere. Plant Physiol Biochem. 2014;85:9-13.

Huang Y, Hickman JE, Wu S. Impacts of enhanced fertilizer applications on tropospheric ozone and crop damage over sub-Saharan Africa. Atmos Environ. 2018;180:117-25. https://doi.org/10.1016/j.atmos env.2018.02.040.

Iffis B, St-Arnaud M, Hijri M. Petroleum contamination and plant identity influence soil and root microbial communities while AMF spores retrieved from the same plants possess markedly different communities. Front Plant Sci. 2017;8:1381.

Ismail Y, Hijri M. Arbuscular mycorrhisation with Glomus irregulare induces expression of potato PR homologues genes in response to infection by Fusarium sambucinum Funct Plant Biol. 2012;39:236-45.

Jain A, Singh A, Singh S, Singh HB. Phenols enhancement effect of microbial consortium in pea plants restrains Sclerotinia sclerotiorum Biol Control. 2015;89:23-32.

Kakabouki I, Tataridas A, Mavroeidis A, Kousta A, Karydogianni S, Zisi C, et al. Effect of colonization of trichoderma harzianum on growth development and CBD content of hemp (Cannabis sativa L.). Microorganisms. 2021;9:518.

Kakani V, Reddy K, Zhao D, Mohammed A. Effects of ultraviolet-B radiation on cotton (Gossypium hirsutum L.) morphology and anatomy. Ann Bot. 2003;91:817-26.

Kaneshima H, Mori M, Mizuno N. Studies on cannabis in Hokkaido (Part 6). The dependence of cannabis plants on iron nutrition. Hokkaidoritsu Eisei Kenkyushoho. 1973;23:3-5.

Köberl M, Schmidt R, Ramadan EM, Bauer R, Berg G. The microbiome of medicinal plants: diversity and importance for plant growth, quality, and health. Front Microbiol. 2013;4:400. https://doi.org/10.3389/ fmicb.2013.00400.

Korenblum E, Dong Y, Szymanski J, Panda S, Jozwiak A, Massalha H, et al. Rhizosphere microbiome mediates systemic root metabolite exudation by root-to-root signaling. Proc Natl Acad Sci. 2020;117:3874-83.

Krejci Z. Changes with maturation in the amounts of biologically interesting substances of cannabis. In C. R. B. Joyce and S. H. Curry (Eds.). The botany and chemistry of Cannabis. London: Churchill; 1970. p. 49.

Kurtz ZD, Müller CL, Miraldi ER, Littman DR, Blaser MJ, Bonneau RA. Sparse and compositionally robust inference of microbial ecological networks. PLoS Comput Biol. 2015;11:e1004226.
Kusari P, Kusari S, Spiteller M, Kayser O. Endophytic fungi harbored in Cannabis sativa L.: diversity and potential as biocontrol agents against host plantspecific phytopathogens. Fungal Diversity. 2012;60:137-51.

Landi S, Berni R, Capasso G, Hausman J-F, Guerriero G, Esposito S. Impact of Nitrogen Nutrition on Cannabis sativa: An Update on the Current Knowledge and Future Prospects. Intern J Mol Sci. 2019;20(22):5803. https://doi.org/10.3390/ijms20225803.

Latta R, Eaton B. Seasonal fluctuations in cannabinoid content of Kansas marijuana. Econ Bot. 1975;29:153-63.

LaVigne JE, Hecksel R, Keresztes A, Streicher JM. Cannabis sativa terpenes are cannabimimetic and selectively enhance cannabinoid activity. Sci Rep. 2021;11:8232.

Lebeis SL. The potential for give and take in plant-microbiome relationships. Front Plant Sci. 2014;5:287.

Li H-L. An archaeological and historical account of cannabis in China. Econ Bot. 1973;28:437-48.

Liu F, Hewezi T, Lebeis SL, Pantalone V, Grewal PS, Staton ME. Soil indigenous microbiome and plant genotypes cooperatively modify soybean rhizosphere microbiome assembly. BMC Microbiol. 2019;19:201.

Lucaciu R, Pelikan C, Gerner SM, Zioutis C, Kostlbacher S, Marx H, et al. A bioinformatics guide to plant microbiome analysis. Front Plant Sci. 2019;10:1313.

Lydon J, Teramura AH, Coffman CB. UV-B radiation effects on photosynthesis, growth and cannabinoid production of two Cannabis sativa chemotypes. Photochem Photobiol. 1987;46:201-6.

Lyu D, Backer R, Robinson WG and Smith DL. Plant Growth-Promoting Rhizobacteria for Cannabis Production: Yield, Cannabinoid Profile and Disease Resistance. Front Microbiol. 2019;10:1761. https://doi.org/10. 3389/fmicb.2019.01761.

Magagnini G, Grassi G, Kotiranta S. The effect of light spectrum on the morphology and cannabinoid content of Cannabis sativa L. Med Cannabis Cannabinoids. 2018;1:19-27.

Marques JM, da Silva TF, Vollu RE, Blank AF, Ding G-C, Seldin L, Smalla K. Plant age and genotype affect the bacterial community composition in the tuber rhizosphere of field-grown sweet potato plants. FEMS Microbiol Ecol. 2014;88:424-35.

Marti G, Schnee S, Andrey Y, Simoes-Pires C, Carrupt P-A, Wolfender J-L, Gindro K. Study of leaf metabolome modifications induced by UV-C radiations in representative Vitis, Cissus and Cannabis species by LC-MS based metabolomics and antioxidant assays. Molecules. 2014;19:14004-21.

Morvan S, Meglouli H, Lounès-Hadj Sahraoui A, Hijri M. Into the wild blueberry (Vaccinium angustifolium) rhizosphere microbiota. Environ Microbiol. 2020;22:3803-22.

Nelson KM, Bisson J, Singh G, Graham JG, Chen S-N, Friesen JB, et al. The essential medicinal chemistry of cannabidiol (CBD). J Med Chem. 2020;63:12137-55.

Oljira AM, Hussain T, Waghmode TR, Zhao H, Sun H, Liu X, et al. Trichoderma enhances net photosynthesis, water use efficiency, and growth of wheat (Triticum aestivum L.) under salt stress. Microorganisms. 2020;8:1565.

Pagnani G, Pellegrini M, Galieni A, D'Egidio S, Matteucci F, Ricci A, et al. Plant growth-promoting rhizobacteria (PGPR) in Cannabis sativa'Finola' cultivation: an alternative fertilization strategy to improve plant growth and quality characteristics. Ind Crops Prod. 2018;123:75-83.

Pascale A, Proietti S, Pantelides IS, Stringlis IA. Modulation of the root microbiome by plant molecules: the basis for targeted disease suppression and plant growth promotion. Front Plant Sci. 2019;10:1741.

Pate DW. Chemical ecology of Cannabis J Int Hemp Assoc. 1994;2:32-7.

Pichersky E, Raguso RA. Why do plants produce so many terpenoid compounds? New Phytol. 2018;220:692-702.

Potter, D. (2009) The propagation, characterisation and optimisation of Cannabis sativa $\mathrm{L}$ as a phytopharmaceutical. King's College London.

Qadri M, Johri S, Shah BA, Khajuria A, Sidiq T, Lattoo SK, et al. Identification and bioactive potential of endophytic fungi isolated from selected plants of the Western Himalayas. Springerplus. 2013;2:8.

Qin Y, Druzhinina IS, Pan X, Yuan Z. Microbially mediated plant salt tolerance and microbiome-based solutions for saline agriculture. Biotechnol Adv. 2016;34:1245-59.

Renaut S, Daoud R, Masse J, Vialle A, Hijri M. Inoculation with rhizophagus irregularis does not alter arbuscular mycorrhizal fungal community 
structure within the roots of corn, wheat, and soybean crops. Microorganisms. 2020;8:83.

Ryffel F, Helfrich EJ, Kiefer P, Peyriga L, Portais JC, Piel J, Vorholt JA. Metabolic footprint of epiphytic bacteria on Arabidopsis thaliana leaves. Isme J. 2016;10:632-43.

Saloner A and Bernstein N. Response of Medical Cannabis (Cannabis sativa L.) to Nitrogen Supply Under Long Photoperiod. Front. Plant Sci. 2020;11:572293. https://doi.org/10.3389/fpls.2020.572293.

Sapkota R, Knorr K, Jørgensen LN, O'Hanlon KA, Nicolaisen M. Host genotype is an important determinant of the cereal phyllosphere mycobiome. New Phytol. 2015;207:1134-44.

Sasse J, Martinoia E, Northen T. Feed your friends: do plant exudates shape the root microbiome? Trends Plant Sci. 2018;23:25-41.

Scherling C, Ulrich K, Ewald D, Weckwerth W. A metabolic signature of the beneficial interaction of the endophyte paenibacillus sp. isolate and in vitro-grown poplar plants revealed by metabolomics. Mol Plant Microbe Interact. 2009;22:1032-7.

Scott M, Rani M, Samsatly J, Charron J-B, Jabaji S. Endophytes of industrial hemp (Cannabis sativa L.) cultivars: identification of culturable bacteria and fungi in leaves, petioles, and seeds. Can J Microbiol. 2018;64:664-80

Sharma A, Shahzad B, Rehman A, Bhardwaj R, Landi M, Zheng B. Response of phenylpropanoid pathway and the role of polyphenols in plants under abiotic stress. Molecules. 2019;24:2452

Shiponi S, Bernstein N. Response of medical cannabis (Cannabis sativa L). genotypes to P supply under long photoperiod: functional phenotyping and the ionome. Indust Crops Products. 2021;161:113154.

Small E, Beckstead H. Cannabinoid phenotypes in Cannabis sativa Nature. 1973;245:147-8

Small E, Beckstead H. Common cannabinoid phenotypes in 350 stocks of Cannabis, Lloydia. 1973;36:144-65.

Small E, Cronquist A. A practical and natural taxonomy for Cannabis. 1976;Taxon.405-35.

Smith DL, Subramanian S, Lamont JR, Bywater-Ekegard M. Signaling in the phytomicrobiome: breadth and potential. Front Plant Sci. 2015;6:709.

Taghinasab M, Jabaji S. Cannabis microbiome and the role of endophytes in modulating the production of secondary metabolites: an overview. Microorganisms. 2020;8.

Trapp S, Croteau R. Defensive resin biosynthesis in conifers. Annu Rev Plant Biol. 2001;52:689-724.

Turner CE, Hadley K. Constituents of Cannabis sativa L. II: absence of cannabidiol in an African variant. J Pharm Sci. 1973:62:251-5.

Turner CE, Hadley KW. Constituents of Cannabis sativa L. III: Clear and discrete separation of cannabidiol and cannabichromene. J Pharm Sci. 1973;62:1083-6.
Valle, J.R.d., Vieira, J., Aucélio, J.G., and Valio, I. Influence of photoperiodism on cannabinoid content of Cannabis sativa L. Bull Narc. 1978;30:67-8.

van Bakel H, Stout JM, Cote AG, Tallon CM, Sharpe AG, Hughes TR, Page JE. The draft genome and transcriptome of Cannabis sativa Genome Biol. 2011;12:R102

van de Mortel JE, de Vos RC, Dekkers E, Pineda A, Guillod L, Bouwmeester K, et al. Metabolic and transcriptomic changes induced in Arabidopsis by the rhizobacterium Pseudomonas fluorescens SS101. Plant Physiol. 2012;160:2173-88.

Vicente I, Baroncelli R, Morán-Diez ME, Bernardi R, Puntoni G, Hermosa R, et al. Combined comparative genomics and gene expression analyses provide insights into the terpene synthases inventory in Trichoderma Microorganisms. 2020;8:1603.

Vujanovic V, Korber DR, Vujanovic S, Vujanovic J, Jabaji S. Scientific Prospects for Cannabis-Microbiome Research to Ensure Quality and Safety of Products. Microorganisms. 2020;8(2):290. https://doi.org/10.3390/micro organisms8020290.

Walker V, Bertrand C, Bellvert F, Moënne-Loccoz Y, Bally R, Comte G. Host plant secondary metabolite profiling shows a complex, strain-dependent response of maize to plant growth-promoting rhizobacteria of the genus Azospirillum New Phytol. 2011;189:494-506.

Walker V, Couillerot O, Von Felten A, Bellvert F, Jansa J, Maurhofer M, et al. Variation of secondary metabolite levels in maize seedling roots induced by inoculation with Azospirillum, Pseudomonas and Glomus consortium under field conditions. Plant Soil. 2012;356:151-63.

Waterman PG, Mole S. Extrinsic factors influencing production of secondary metabolites in plants. Insect-Plant Interact. 1989:1:107-34.

Winston ME, Hampton-Marcell J, Zarraonaindia I, Owens SM, Moreau CS, Gilbert JA, et al. Understanding Cultivar-Specificity and Soil Determinants of the Cannabis Microbiome. PLoS ONE. 2014;9(6):e99641. https://doi. org/10.1371/journal.pone.0099641.

Zamioudis C, Pieterse CMJ. Modulation of host immunity by beneficial microbes. Mol Plant-Microbe Interact. 2011;25:139-50.

Zarik L, Meddich A, Hijri M, Hafidi M, Ouhammou A, Ouahmane L, et al. Use of arbuscular mycorrhizal fungi to improve the drought tolerance of Cupressus atlantica G. C R Biol. 2016;339:185-96.

\section{Publisher's Note}

Springer Nature remains neutral with regard to jurisdictional claims in published maps and institutional affiliations.
Ready to submit your research? Choose BMC and benefit from:

- fast, convenient online submission

- thorough peer review by experienced researchers in your field

- rapid publication on acceptance

- support for research data, including large and complex data types

- gold Open Access which fosters wider collaboration and increased citations

- maximum visibility for your research: over $100 \mathrm{M}$ website views per year

At BMC, research is always in progress.

Learn more biomedcentral.com/submissions 